\title{
Design of Kicker Magnet and Power Supply Unit for Synchrotron Beam Injection
}

\section{By JU WANG}

Introduction

To inject beams from the positron accumulator ring (PAR) into the synchrotron, a pulsed kicker magnet is used. The specifications of this kicker magnet are listed in Table 1.

Table 1. Design and System Specifications of Kicker Magnet for Injection into the Injector Synchrotron

$\begin{array}{lll}\text { Rise Time }\left(t_{\mathrm{f}}\right) & \leq 500 & \text { ns } \\ \text { Flat Top }\left(\mathrm{t}_{\mathrm{f}}\right) & 29 & \text { ns } \\ \text { Fall Time }\left(\mathrm{t}_{\mathrm{f}}\right) & \leq 500 & \text { ns } \\ \text { Peak Magnetic Field (B) } & 0.0308 & \text { T (for } 450 \mathrm{MeV} \text { ) } \\ & 0.0445 & \text { T (for } 650 \mathrm{MeV} \text { ) }\end{array}$

Field Dimensions:

\begin{tabular}{|c|c|}
\hline Gap Height & 4 \\
\hline Gap Width* & 5.75 \\
\hline Length & 25 \\
\hline epetition Rate & 2 \\
\hline
\end{tabular}

* This gap width is determined by the length of the major axis of the elliptic ceramic vacuum chamber and is slightly different from the gap width used to calculate the magnet inductance.

\section{Magnet}

Similar to the designs for the PAR kicker/bumper magnets and the storage ring beam abort kicker magnets, the magnet for the synchrotron beam injection kicker is a window-frame magnet.[1] The cross section of the magnet, shown in Figure 1, is the same as that for the storage ring beam abort kicker magnet since their ceramic chambers have the same cross section. 


\section{DISCLAIMER}

This report was prepared as an account of work sponsored by an agency of the United States Government. Neither the United States Government nor any agency thereof, nor any of their employees, make any warranty, express or implied, or assumes any legal liability or responsibility for the accuracy, completeness, or usefulness of any information, apparatus, product, or process disclosed, or represents that its use would not infringe privately owned rights. Reference herein to any specific commercial product, process, or service by trade name, trademark, manufacturer, or otherwise does not necessarily constitute or imply its endorsement, recommendation, or favoring by the United States Government or any agency thereof. The views and opinions of authors expressed herein do not necessarily state or reflect those of the United States Government or any agency thereof. 


\section{DISCLAIMER}

Portions of this document may be illegible in electronic image products. Images are produced from the best available original document. 


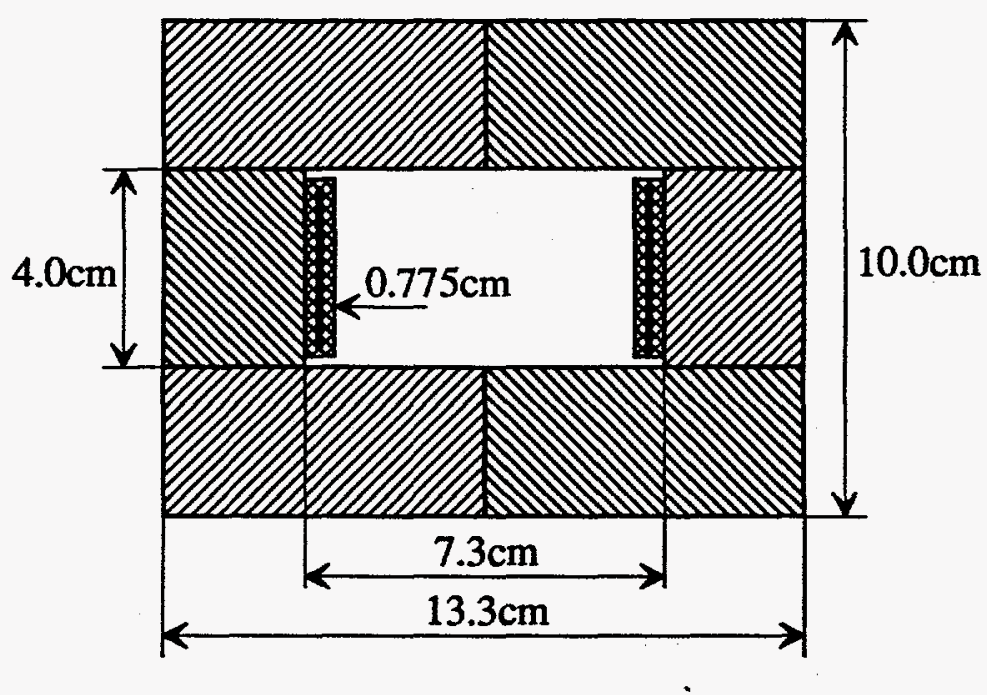

Figure 1. Cross section of the synchrotron injection kicker magnet

Since the required rise time, $500 \mathrm{~ns}$, of the magnetic field is relatively slow, it is unnecessary to divide the magnet into two half-turn magnets. The top and bottom parts of the magnet are still divided into two blocks because of the limitation of the largest ferrite blocks available, but there will be no copper foil inserted between ferrites.

The flux density, $\mathbf{B}$, in the air gap can be calculated as

$$
\text { B }=\frac{\mu_{0} I}{g}
$$

where $I$ is the current in the coil and $g$ is the length of the air gap. This equation is derived under the assumptions that the magnetic field inside the air gap is uniform and the magnetic field intensity inside the ferrites is negligible compared with that in the air gap. When $\mathbf{B}$ is available, the current required to produce B can be obtained using

$$
I=\frac{\mathbf{B} g}{\mu_{0}}
$$

For the magnet in Figure 1 to generate a magnetic field of $0.0445 \mathrm{~T}$, the required current will be $1416.5 \mathrm{~A}$. 
The inductance of the coil can be calculated as

$$
L=\frac{\mu_{0} w l}{g}
$$

where $w$ is the width of the air gap (the distance between the centers of two conductors) and $l$ is the effective length of the magnet. For the given geometry of the magnet, the inductance $L$ is equal to $512.5 \mathrm{nH}$ if the end effect is ignored.

The magnet will be constructed with ferrite blocks, CMD5005 manufactured by Ceramic Magnetics, Inc. The thickness of the ferrite blocks is selected as $3 \mathrm{~cm}$. This results in a magnetic field of about 484 Gauss inside the ferrites, below its saturation point.

The magnet will be connected to a pulse forming network (PFN). Therefore, capacitors or capacitor-resistor strings need to be added to the magnet to match the PFN characteristic impedance. In this design two capacitor-resistor strings will be added to the magnet to form a $\pi$ circuit. The capacitance, $C$, of the capacitors is chosen such that

$$
\sqrt{\frac{L}{2 C}}=Z_{P F N}
$$

The resistance of the resistors is chosen equal to the PFN characteristic impedance. The purpose of adding resistors to the capacitors is to minimize the reflection when the voltage and current waveforms travel from the PFN to the magnet.

\section{Pulse Forming Network}

There are various types of pulse forming networks for different requirements.[2] A suitable pulse forming network for the synchrotron beam injection kicker consists of coaxial cables. The criterion for selecting the coaxial cables is such that the characteristic impedance of 
the cable should be as low as possible, while the pulse rise time is satisfied because the required PFN voltage is low for low impedance cables. The available low impedance cable is YR10914, by Belden Corporation. The nominal values of the inductance and the capacitance of the cable are $101.68 \mathrm{nH} / \mathrm{m}$ and $377.2 \mathrm{pF} / \mathrm{m}$, respectively. The resulting characteristic impedance is $16.4 \Omega$ assuming the cable is ideal, i.e. lossless. (The estimated value from the manufacture is $13 \Omega$.) The PFN is made of four cables connected in parallel. The length of the cables is 25 meters. The number of the cables in parallel and the length of the cables are determined by computer simulation.

With this PFN, the capacitance and the resistance of the capacitor-resistor strings needed by the magnet to match the PFN characteristic impedance are approximately $15 \mathrm{nF}$ and $4 \Omega$, respectively. A $4 \Omega$ resistor is also needed to terminate the network. This resistor also serves as the load for the kicker unit.

Four, eight (8) meter long cables are used to connect the magnet to the load resistor so that the load resistor and switching tube (thyratron) and the associated control circuit can be located outside the tunnel. This improves the accessibility of these components and makes them less subject to radiation damage. Due to these cables, however, there is a time delay between the time the thyratron is triggered and the time the magnetic field starts rising. This delay time is about $50 \mathrm{~ns}$ since the propagation time of the cables is approximately $6.19 \mathrm{~ns} / \mathrm{m}$.

\section{High Voltage DC Power Supply and Switching Tubes}

When the PFN, magnet and load resistor are chosen, the required high voltage dc power supply and switching tubes (tetrode and thyratron) can be determined.

The voltage drop on the load resistor, when the thyratron is turned on, is the product of the current and the resistance of the resistor and equal to one half of the initial PFN voltage if the 
load resistor matches the PFN characteristic impedance. Assuming that the load current is equal to the desired magnet current, $1416.5 \mathrm{~A}$ in this case, the voltage drop will be $5.81 \mathrm{kV}$. Then, the initial PFN voltage is $11.62 \mathrm{kV}$. Therefore a dc power supply with the output voltage equal to or greater than $11.62 \mathrm{kV}$ will be required to charge the PFN.

The total capacitance in the circuit is equal to $79.8 \mathrm{nF}$. The time interval between two discharging pulses is $500 \mathrm{~ms}$ since the kicker will be operated at a repetition rate of $2 \mathrm{~Hz}$. With $2 \mathrm{~ms}$ reserved for the discharging of the PFN and the recovery of the thyratron, the charging time can be as long as $498 \mathrm{~ms}$. The circuit will be charged in resistive charging mode. The time constant of the charging circuit should be less than $99.6 \mathrm{~ms}$. Then the total resistance in the circuit during the charging should be less than $1.25 \mathrm{M} \Omega$. Thus, the output current of the $\mathrm{dc}$ voltage power supply should be greater than $9.7 \mathrm{~mA}$. A standard commercial $15 \mathrm{kV}, 20 \mathrm{~mA} \mathrm{dc}$ power supply will be sufficient for charging the circuit.

The charging of the PFN will be controlled by a tetrode. An EIMAC tetrode, 8960 , will be used. The maximum ratings of EIMAC 8960 are $50 \mathrm{kV}$ and $12 \mathrm{~A}$, which are much greater than the required charging voltage and current. However, there are design and maintenance advantages for choosing this tetrode since the same tetrode will be used for other kicker units.

Since the beam injection kicker is operated at a low frequency, $2 \mathrm{~Hz}$, the average load current is very low. The main criteria for selecting the thyratron will be the maximum operating voltage and current. The thyratron CX1154 by EEV rated at maximum $40 \mathrm{kV}$ and $3 \mathrm{kA}$ can be used.

\section{Computer Simulation Results of the Injection Kicker Circuit}

The schematic of the synchrotron beam injection kicker unit is shown in Figure 2. This unit has been simulated with PSpice program, by MicroSim Corporation, Irvine, CA. The 


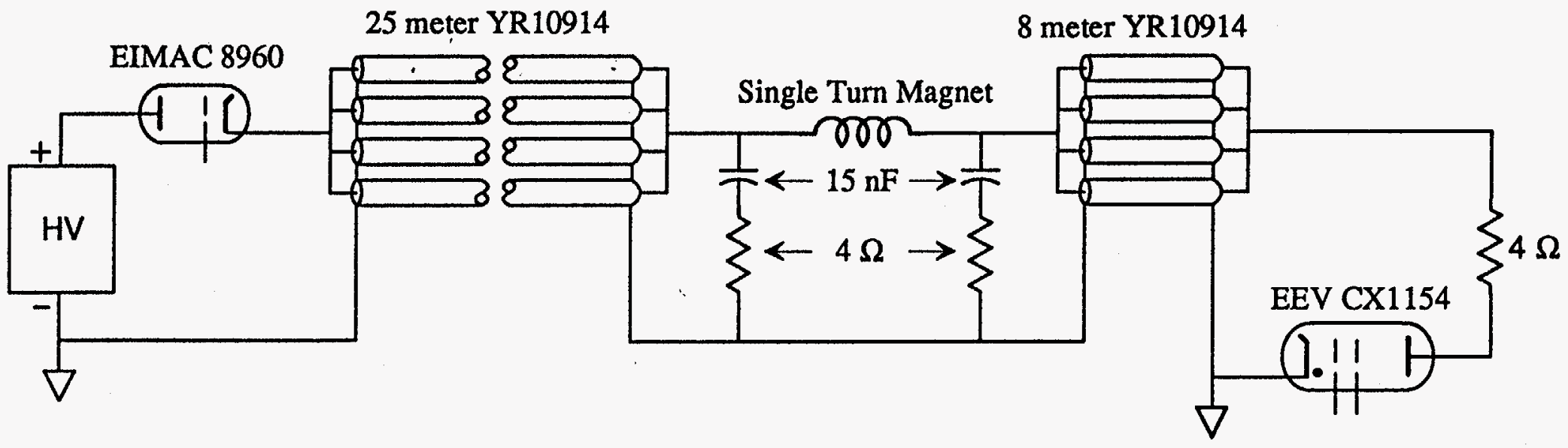

The inductance of the single turn magnet is $0.5125 \mathrm{mH}$.

The PFN voltage is $10.88 \mathrm{kV}$.

Figure 2. Circuit configuration of the synchrotron beam injection kicker unit 
simulation does not include the high voltage dc power supply and the tetrode. The thyratron is represented by a $100 \mathrm{~V}$ dc voltage source in series with a $20 \mathrm{nH}$ inductor. The voltage source represents the thyratron on-state voltage drop and the inductor simulates time delay due to the thyratron turn-on process.

The simulation shows that to achieve the required magnet current, the PFN voltage needs to be $10.88 \mathrm{kV}$, less than the calculated value of $11.62 \mathrm{kV}$. This is due to the fact that the magnet is a lumped element and cannot perfectly match the PFN characteristic impedance with added capacitor-resistor strings. Furthermore, the thyratron causes some mismatch between the load resistor and the PFN. This can be seen from the high frequency oscillation in the load resistor current. Some of the simulation results are shown in Figure 3 through Figure 6.

Figure 3 shows currents in the magnet and load resistor. The maximum magnet current occurs at 342 ns. During the 29 ns flat top, the magnet current is within $\pm 0.05 \%$ of the specified value. Figure 3 also shows that the magnet current has negative overshoot. However, a longer simulation, shown in Figure 4, shows that the magnet current is $0.66 \%$ of the peak value at 1.57 $\mu \mathrm{s}$. The synchrotron revolution time is $1.228 \mu \mathrm{s}$. Thus, when the beam passes the beam injection kicker for the second time, the magnetic field is almost zero.

Figure 5 shows the voltages at different points of the PFN and magnet. It describes the propagation of the voltage waveform. Figure 6 shows the currents in the capacitor-resistor strings. These curves can be used to choose the capacitors and resistors.

\section{Reference}

[1] Wang, J. and Volk, J., "Design of Kicker/Bumper Magnet and PFN for PAR", ANL Light-Source-Note, LSN-156, October 15, 1990.

[2] Sarjeant, James W. and Dollinger, R. E., "High-Power Electronics", TAB BOOKS Inc., 1989. 


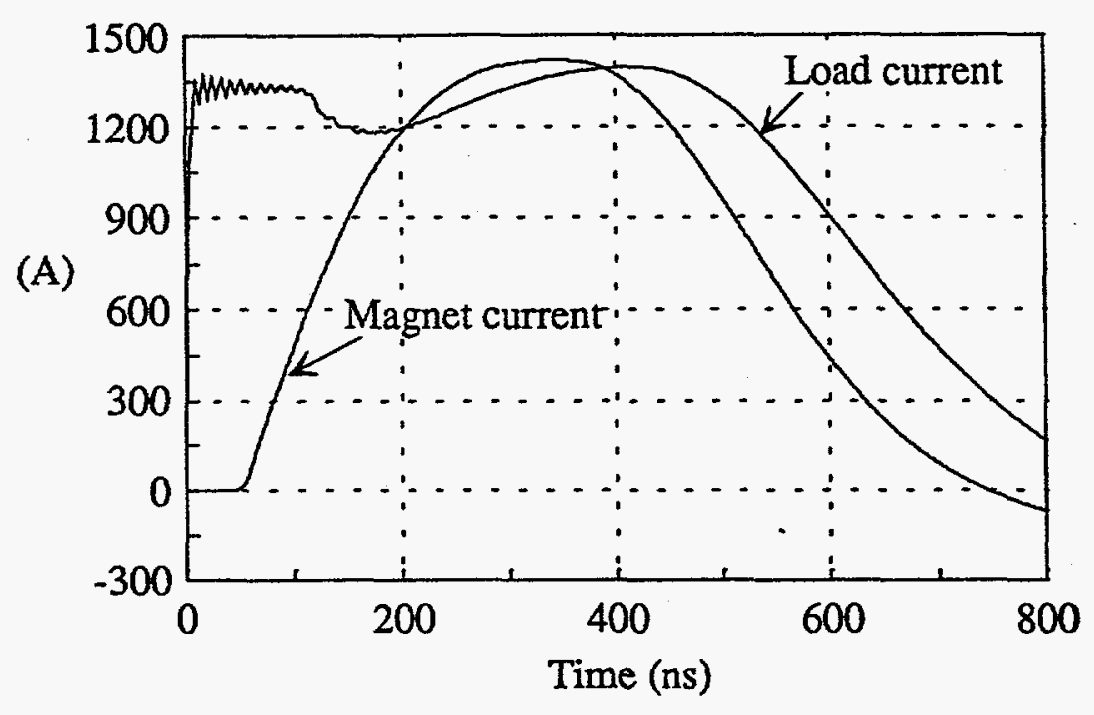

Figure 3. Currents in the magnet and the load resistor

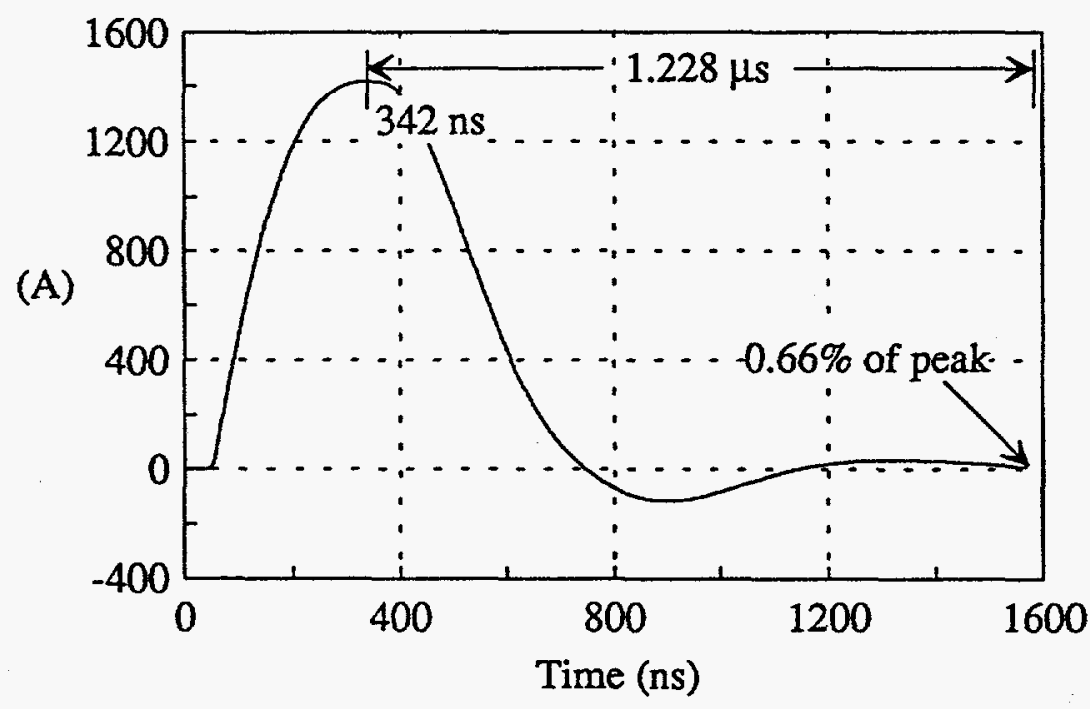

Figure 4. Magnet current 


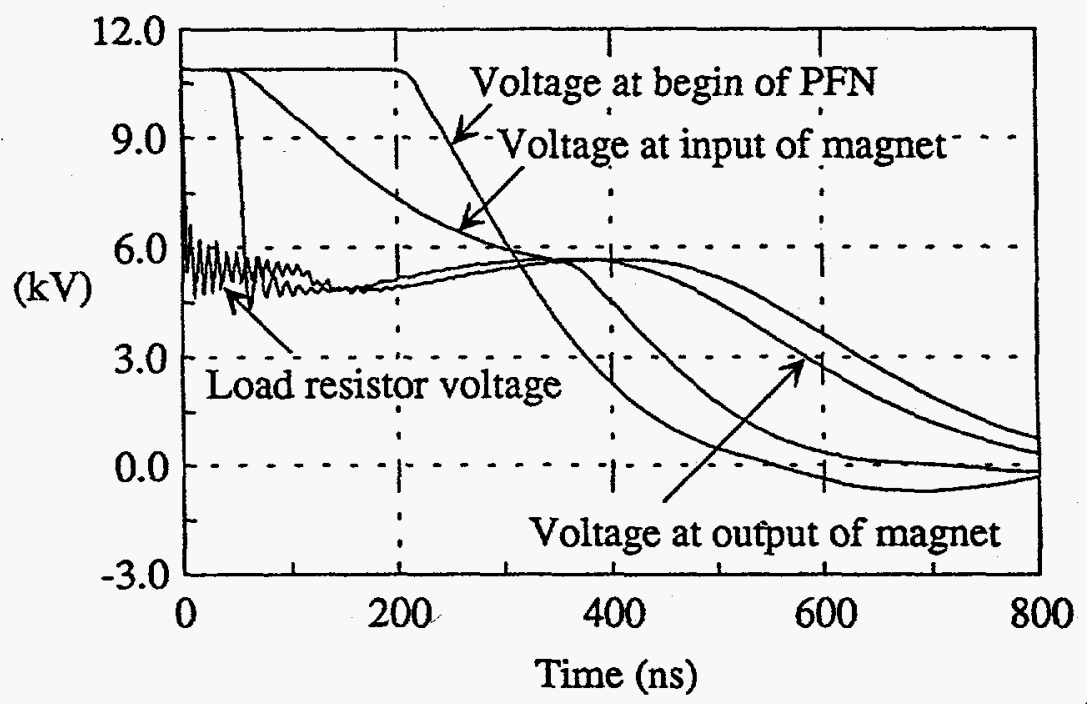

Figure 5. Voltages at different points during pulsing

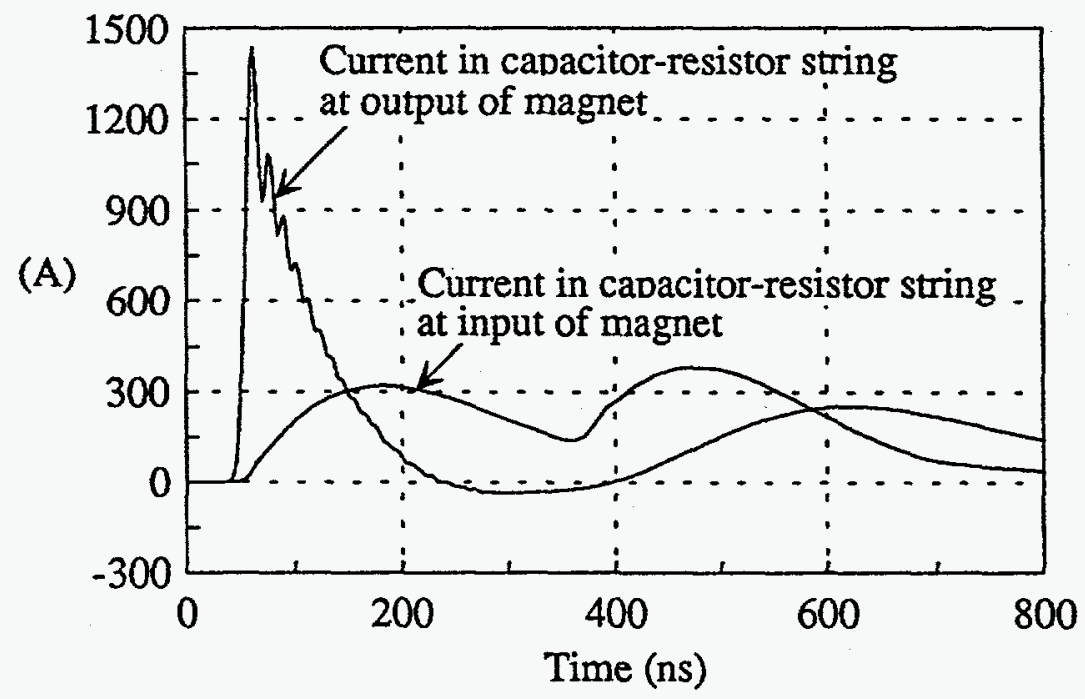

Figure 6. Currents in the capacitor-resistor strings 